\title{
Characteristics of ovarian tumors in Lebanon: 20 years of experience in a Lebanese tertiary center
}

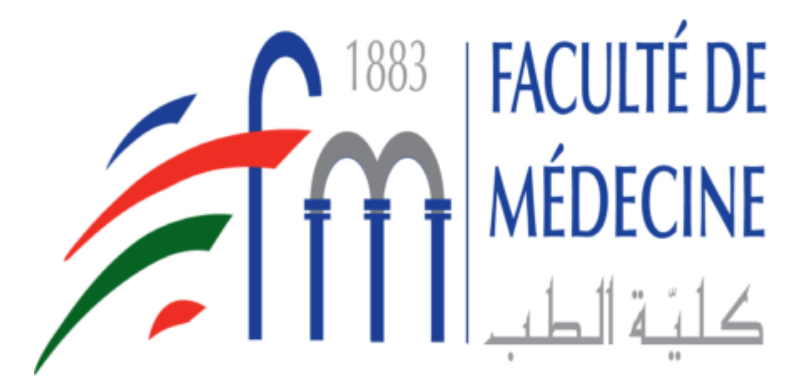

Eid R, Lilly E, Haddad FG, Kesrouani C, Kourie HR, Khaddage A, Moubarak M, Atallah D

Hôtel-Dieu de France University Hospital, Saint Joseph University, Beirut, Lebanon

\section{AIM}

To report the epidemiological and histological features of ovarian tumors in Lebanon

\section{METHODS}

This is a retrospective study evaluating the characteristics of borderline and malignant ovarian tumors diagnosed in 20 years (from 1997 to 2017) at the Hôtel Dieu de France, University Hospital of Saint Joseph University in Beirut in Lebanon. The data was extracted from the computerized registers of the hospital's pathology laboratory. Statistical analysis was performed using SPSS 24.0 software.

\section{RESULTS}

- 1137 ovarian lesions were reported, of which 695 $(61.12 \%)$ were benign, 50 (4.4\%) borderline, 361 $(31.75 \%)$ malignant and $31(2.73 \%)$ were unspecified. Of the 361 malignant lesions, 54 $(4.75 \%)$ were metastases from another extraovarian primitive.

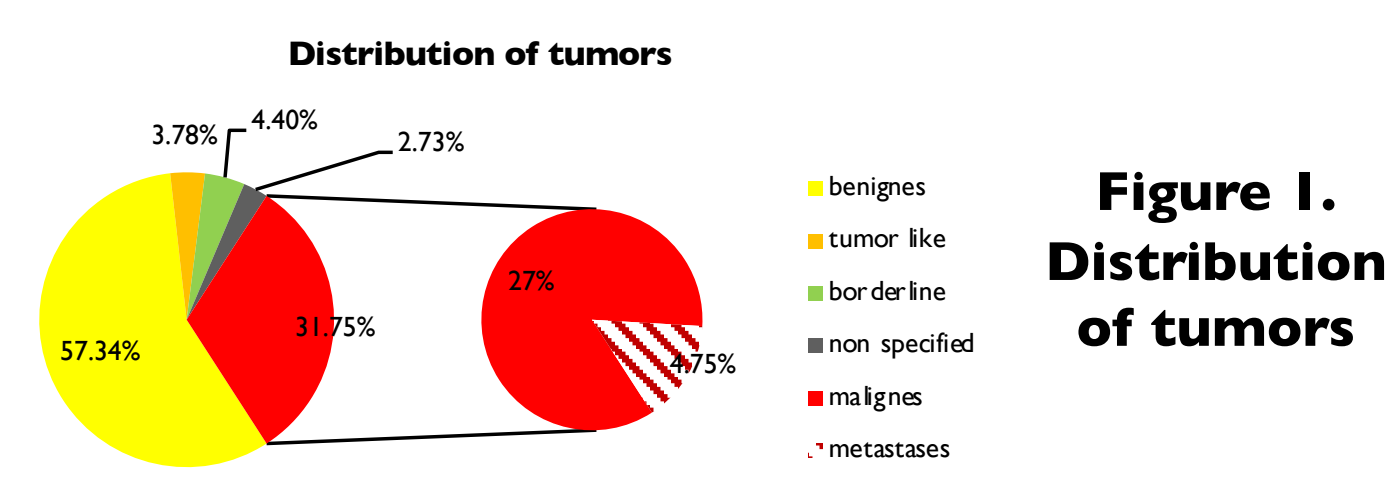

- Of the 652 benign neoplastic ovarian tumors, epithelial tumors, stromal and sex cords tumors, germ cell tumors and tumors from the dermoid cyst were 306 (46.93\%), 70 (10.73\%), 268 (41.1\%). $\%)$ and $8(1.24 \%)$.

- The most common benign neoplastic tumor was mature cystic teratoma representing 268 cases (41.1\%), followed by $170(26.07 \%)$ serous cystadenomas, and $80(12.2 \%)$ mucinous cystadenomas. Of the 361 malignant ovarian tumors, $246(68.1 \%)$ were malignant surface epithelial tumors. Germ cell malignancies, stromal tumor and sex cords, and metastatic carcinoma were 25 (6.9\%), 22 (6.1\%), and 54 (15\%), respectively. High grade serous cystadenocarcinoma was the most common

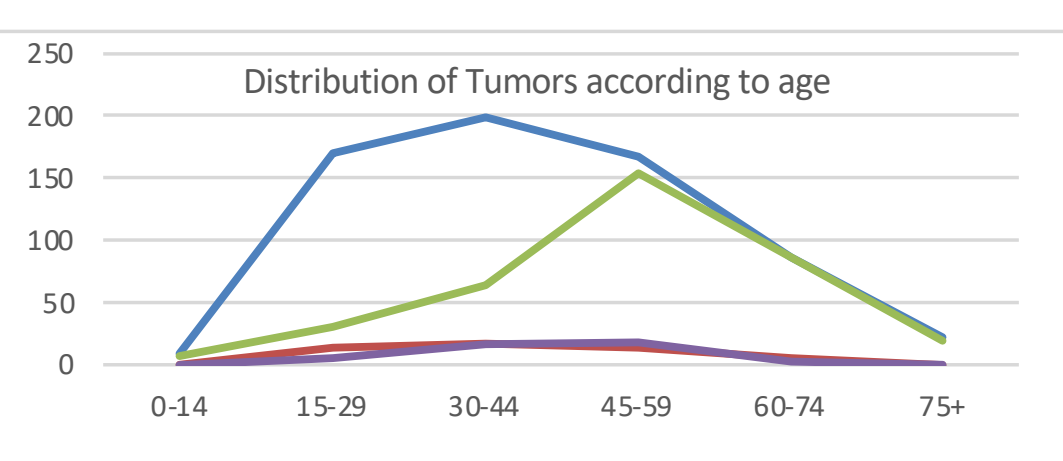

Figure 2. Distribution of tumors according to age malignant tumor with 147 cases $(40.7 \%)$.

\section{CONCLUSION}

The epidemiological characteristics of ovarian tumors in Lebanon are compatible with those published in Western countries and in Asia. This study is the first of its kind in Lebanon and is a database for further research. 